\title{
Randomised controlled trial of anti-smoking advice: final (20 year) results
}

\author{
Geoffrey Rose, Linda Colwell
}

\begin{abstract}
Study objective-The aim was to measure experimentally the effects in middle aged men of stopping smoking.

Design-The study was a randomised controlled trial.

Setting and subjects-The subjects were 1445 male smokers, initially aged 40-59 years, who were selected from the Whitehall study survey of 16016 civil servants on the basis of a high risk of cardiorespiratory disease.
\end{abstract}

Main results-During the next 20 years there were 620 deaths (231 from coronary heart disease), 96 cases of lung cancer, and 159 other cancers. Comparing the intervention with the normal care group, total mortality was $7 \%$ lower, fatal coronary heart disease was $13 \%$ lower, and lung cancer (deaths + registrations) was $11 \%$ lower. An excess rate for other cancers, reported previously, did not persist into the second decade of the trial.

Conclusions-The results are consistent with observational studies, implying that smoking cessation by middle aged men substantially improves their chances of avoiding lung cancer or a fatal heart attack. Our estimate from the trial is that out of every 100 men who stopped smoking, between six and 10 were in consequence alive 20 years later.

This is the only randomised single factor trial to have measured the health outcomes of antismoking advice, and it is likely to remain so. We have already reported the results after five and 10 years. ${ }^{12}$ All participants have now been followed for 20 years, and we present our final report.

\section{Methods}

Details were published previously. ${ }^{1}$ In $1968-70$ we examined 16016 male civil servants aged 40 to 59 years in the first Whitehall study. The results were used to select the 1445 cigarette smokers with the highest cardiorespiratory risk scores, who were randomly allocated to intervention (714 men) or normal care (731 men). Those in the intervention group received individual advice on the relation of smoking to health. Most then declared a wish to stop smoking and they received further support over the next 12 months, averaging a further four visits.

After one year in the trial, $63^{\circ}{ }_{0}$ of the $84^{\circ}{ }_{0}$ respondents in the intervention group said that they no longer smoked cigarettes, but about a third of these men still smoked a pipe or cigars. Over the first 10 years of the trial the reported net reduction in cigarettes smoked was $53^{\circ}{ }_{0}$ (eight cigarettes daily); but by the end of the 10 years this net reduction had fallen to $30^{\circ}{ }_{0}$, due mainly to reduced consumption by the "normal care" group (reflecting a general decline in smoking among civil servants). Due to late or amended notifications, figures for the 10 year results differ slightly from those in the previous report. ${ }^{2}$

Over the first 10 years of follow up, mortality in the intervention group was $18^{\circ}{ }_{o}$ lower than in the "normal care" group for coronary heart disease and $23^{\circ}{ }_{0}$ lower for lung cancer. Deaths from non-lung cancers were however higher (28 $v 13$ deaths). This excess showed no site specificity, and it derived equally from unexpectedly high rates in intervention men and low rates in those receiving normal care. Among intervention men it was unrelated to smoking cessation. The interpretation was uncertain, but it was thought likely to be due to chance. ${ }^{2}$

Follow up of all men has continued, through the good offices of the National Health Service Central Registry, based on death certificates and cancer registrations. No attempt has been made to establish the current smoking habits of survivors, most of whom are now retired and hard to trace.

\section{Results}

Table I presents life table probabilities for the main outcomes at various stages of the trial. As compared with the first decade, the advantage to the intervention group for fatal coronary heart disease during the second decade, though continuing, was a little smaller $\left(-9^{\circ}{ }_{0} v-18^{\circ}{ }_{0}\right)$; for lung cancer (deaths + other registrations) the advantage was maintained $\left(-12^{\circ}{ }_{0} v-8^{\circ}{ }_{0}\right)$. For non-lung cancers (deaths + registrations) there was concern during the first decade at a remarkable excess in the intervention group, but this did not persist, and in fact the incidence during the second decade was $8^{\circ}$ o lower in the intervention group.

Taking the results from table I for the whole duration of the trial, the intervention group experienced overall a $13^{\circ}$ o reduction $\left(95^{\circ}{ }_{0} \mathrm{CI}\right.$ -33 to $+13^{\circ}{ }_{0}$ ) in fatal coronary heart disease, an $11^{\circ}{ }_{0}$ reduction $\left(95^{\circ}{ }_{0} \mathrm{CI}-41\right.$ to $\left.+38^{\circ}{ }_{0}\right)$ in lung cancer, a $16^{\circ}{ }_{0}$ excess $\left(95^{\circ}{ }_{0} \mathrm{CI}-15\right.$ to $\left.+59^{\circ}{ }_{0}\right)$ for non-lung cancer, and a $7^{\circ}{ }_{0}$ reduction $(95 \mathrm{CI}-20$ to $+9^{\circ}{ }_{o}$ ) for total mortality.

Table II presents the findings for two separate age groups (40-49 and 50-59 years at entry; ie, 60-69 and 70-79 years for survivors). For the older men there is a modest advantage to the intervention group of around $10^{\circ}{ }_{0}$ for coronary 
heart disease and total mortality, and the latter is consistent over both the earlier and the later periods of follow up. For the younger men on the other hand there is during the earlier period a rather large excess of coronary heart disease deaths in the intervention group, giving way later to an advantage $(-5 \%)$. For lung cancer the advantage was modest at first, but later it increased. A persisting excess of non-lung cancers prevented any overall mortality benefit for this younger age group.

The results have also been analysed according to various entry characteristics (table III). (Because of small numbers and multiple subgroups hypotheses the findings must be viewed with caution.) For fatal coronary heart disease the advantage to the intervention group was unrelated to plasma cholesterol level; but among the 1304 men with no ischaemic type electrocardiograph changes there was a reduction in coronary heart disease of $13 \%$, compared with an excess of $2 \%$ in men with such changes. The presence of exertional dyspnoea at entry (158 men) was associated with a large advantage to intervention, both for total mortality $(-30 \%)$ and fatal coronary heart disease $(-46 \%)$.

\section{Discussion}

This trial was necessary because the much larger observational studies might have been influenced by selection bias. Ex-smokers are not a random sample of smokers, being weighted on the one hand by health conscious and socioeconomically advantaged individuals whose health prospects were anyway better than average, and on the other hand by those who stopped smoking because of ill health. The net effect of these two opposite biases is uncertain, and its resolution called for a randomised trial.

Several factors have reduced the power of the trial, including wide confidence intervals (reflecting insufficient numbers) and the diluting effects of incomplete "compliance" in the intervention group and of a progressive reduction in smoking by control men: beyond 10 years there was only a small difference in smoking rates between the groups. Making allowance for these effects it can be said that the results are generally consistent with the expectations derived from observational studies, implying that smoking cessation by middle aged men substantially improves their chances of avoiding lung cancer or a fatal heart attack.

After 20 years there were about $3^{\circ}{ }_{0}$ more survivors in the intervention than in the control group. To estimate the true effect of smoking this figure should probably be doubled, in order to allow for the fact that only about half of them actually stopped smoking, and increased further because of smoking cessation by control men. A best estimate would therefore be that out of every 100 men who stopped smoking, between six and 10 were in consequence alive 20 years later.

In our previous report ${ }^{2}$ we concluded that "after exhaustive analysis of the data, we think
Table I Life table probabilities of death, or death plus cancer registration, in normal care (NC) and intervention (I) groups (all ages). Values are percentages, with numbers of events in brackets

Table II Rate ratios (and total numbers of events): intervention normal care, for ages at entry: (a) 40-49 years, and (b) 50-59 years

Table III 20 Year mortality ratios (intervention/normal care), for coronary heart disease and all causes, according to findings at initial examination

\begin{tabular}{|c|c|c|c|c|c|}
\hline $\begin{array}{l}\text { Years } \\
\text { in trial }\end{array}$ & Group & $\begin{array}{l}\text { Coronary } \\
\text { heart disease }\end{array}$ & $\begin{array}{l}\text { Lung cancer, } \\
\text { including } \\
\text { registrations }\end{array}$ & $\begin{array}{l}\text { Other cancers, } \\
\text { including } \\
\text { registrations }\end{array}$ & $\begin{array}{l}\text { All causes } \\
\text { of death }\end{array}$ \\
\hline $0-10$ & $\begin{array}{l}\text { NC } \\
\text { I } \\
\text { I/NC }\end{array}$ & $\begin{array}{l}8.9(62) \\
7.3(49) \\
0.82\end{array}$ & $\begin{array}{l}3.6(25) \\
3.3(22) \\
0.92\end{array}$ & $\begin{array}{l}4 \cdot 0(27) \\
6.7(45) \\
1.68\end{array}$ & $\begin{array}{l}17.8(130) \\
17.2(123) \\
0.97\end{array}$ \\
\hline $10-20$ & $\begin{array}{l}\text { NC } \\
\text { I } \\
\text { I/NC }\end{array}$ & $\begin{array}{c}11.0(64) \\
10.0(56) \\
0.91\end{array}$ & $\begin{array}{l}5 \cdot 1(26) \\
4.5(23) \\
0.88\end{array}$ & $\begin{array}{l}8.3(45) \\
7.6(42) \\
0.92\end{array}$ & $\begin{array}{c}26.6(194) \\
24 \cdot 2(173) \\
0.91\end{array}$ \\
\hline $0-20$ & $\begin{array}{l}\mathrm{NC} \\
\mathrm{I} \\
\mathrm{I} / \mathrm{NC}\end{array}$ & $\begin{array}{c}19 \cdot 9(126) \\
17 \cdot 3(105) \\
0 \cdot 87\end{array}$ & $\begin{array}{l}8.8(51) \\
7 \cdot 8(45) \\
0.89\end{array}$ & $\begin{array}{c}12 \cdot 3(72) \\
14 \cdot 3(87) \\
1 \cdot 16\end{array}$ & $\begin{array}{c}44.4(324) \\
41.5(296) \\
0.93\end{array}$ \\
\hline
\end{tabular}


that the difference in non-lung cancer mortality and incidence in this trial is more likely to be due to chance than to an effect of intervention." After another 10 years of follow up, during which this excess incidence did not persist, there is no reason to change this tentative conclusion.

There is now the additional subgroup finding of an excess of coronary heart disease deaths among younger men in the intervention group during the early years of the trial; but the numbers were not large, there was no prior hypothesis, and examination of multiple subgroups further reduces the strength of the finding. Nevertheless a similar early excess was noted in the United Kingdom section of the large WHO European trial of multifactorial prevention of coronary heart disease, ${ }^{3}$ in which anti-smoking advice was one of the major interventions. Smoking cessation in the general population, like other preventive measures, tends to be a more gradual process than in experimental studies. Thus in our trial in civil servants, of those in the intervention group who stopped smoking at any stage, $80 \%$ did not smoke another cigarette after the first visit. Perhaps there is a physiological adaptation to a chronic adverse exposure, such that its abrupt withdrawal could induce a period of destabilisation, analogous to the effects of withdrawing alcohol or other addictive drugs.

Extended follow up of morbidity was not possible in our trial, but it must be remembered that the benefits of smoking cessation are not confined to mortality. In our first report ${ }^{1}$ we noted that early in the trial the intervention group experienced a reduced prevalence of nasal obstruction (the commonest benefit), productive cough and dyspnoea; and although lost ventilatory function was not recovered, its subsequent rate of decline was slower than in control men.

1 Rose G, Hamilton PJS. A randomised controlled trial of the effect on middle-aged men of advice to stop smoking. $f$ Epidemiol Community Health 1978; 32: 275-81.

2 Rose G, Hamilton PJS, Colwell L, Shipley MJ. A randomised controlled trial of anti-smoking advice: 10 year results. $\mathcal{f}$ Epidemiol Community Health 1982; 36: 102-8.

3 Rose G, Tunstall-Pedoe HD, Heller RF. UK Heart Disease Prevention Project. Incidence and mortality results. Lancet 1983; i: $1062-6$. 